\title{
O INCIDENTE DE RESOLUÇÃO DE DEMANDAS REPETITIVAS APLICADO AO DIREITO DO CONSUMIDOR
}

\author{
Andressa Solon Borges ${ }^{78}$ \\ Carlos André Maciel Pinheiro Pereira ${ }^{79}$
}

\begin{abstract}
RESUMO
O presente artigo objetiva discutir o papel conferido ao instituto de resolução de demandas repetitivas dentro da sistemática processual e sua aplicação nos processos baseados no direito do consumidor. Utiliza o método dedutivo para realização de pesquisa exploratória e qualitativa. Compreende que o incidente de resolução de demandas repetitivas é uma ferramenta criada pelo legislador para salvaguardar a segurança jurídica e desafogar os tribunais com o fim de assegurar a celeridade processual. Considera que as demandas consumeristas seriadas são fruto da pósmodernidade, eis que as relações de consumo fazem parte da própria identidade do sujeito, de modo que os problemas não resolvidos entre consumidor e fornecedor aportam no poder judiciário. Visualiza a aplicação do incidente de demandas repetitivas nas relações de consumo pelos tribunais brasileiros, com fundamento em estudos estáticos. Por fim, conclui que o incidente de resolução de demandas repetitivas, apesar de sua tímida utilização, implica em uma ferramenta hábil para sistematizar o acesso à justiça como ordem de valores a ser entregue ao consumidor.
\end{abstract}

Palavras-chave Incidente de resolução de demandas repetitivas. Relações de consumo. Acesso à justiça no direito de consumidor.

\section{INTRODUÇÃO}

Com o ingresso na pós-modernidade, dois fatos ganham maior proporção nas sociedades contemporâneas: consumo e conflito. A tendência é que as pessoas consumam cada vez mais, como

\footnotetext{
${ }^{78}$ Mestra em Direito Constitucional pela Universidade Federal do Rio Grande do Norte (UFRN). Especialista em Direito Civil pela Faculdades Integradas de Jacarepaguá (FIJ). Especialista em Direito Público pela Instituto de Ensino Superior de Fortaleza (IESF). Bacharela em Direito pelo Centro Universitário do Rio Grande do Norte (UNIRN). Técnica Judiciária do Tribunal de Justiça do Rio Grande do Norte (TJRN). E-mail: solonandressa@ gmail.com

79 Doutorando em Filosofia do Direito pela Universidade Federal de Pernambuco (UFPE). Mestre em Direito Constitucional pela Universidade Federal do Rio Grande do Norte (UFRN). Especialista em Direito Tributário pelo Instituto Brasileiro de Estudos Tributários (IBET). Bacharel em Direito pelo Centro Universitário do Rio Grande do Norte (UNI-RN). Professor DNS I da Universidade Potiguar (UnP). Advogado. E-mail: candremaciel@ hotmail.com
} 
forma de se destacar entre os demais, eis que toda a conjuntura econômica apropria-se do consumo como um dos alicerces das relações intersubjetivas. De outro orbe, os conflitos se mostram uma constante cada vez mais presente, tendo em mira o pluralismo que reveste toda a sociedade e a grande quantidade de divergências que disto emanam.

Diferentes não seriam os conflitos que advêm das relações de consumo, cujo aumento quantitativo e qualitativo acompanha o desenvolvimento socioeconômico. Os dissensos entre consumidor e fornecedor findam ingressando, de forma seriada, no poder judiciário. Frente a esta situação, o Código de Processo Civil de 2015 introduz o incidente de resolução de demandas repetitivas, como forma de superar questões recorrentes no âmbito dos tribunais.

Cabe questionar: no que consiste o incidente acima mencionado? Quais são as peculiaridades das relações de consumo que as tornam seriadas? É possível utilizar o instituto mencionado para resolver demandas envolvendo o consumidor? É com o objetivo de responder a essas problemáticas que a presente investigação será desenvolvida, com o fito de esclarecer as potencialidades do incidente de resolução de demandas repetitivas para as demandas de consumo.

Será produzida uma pesquisa de ordem qualitativa, do tipo exploratória e com suporte no método dedutivo, cuja aplicação orientará a análise do Código de Processo Civil e das obras bibliográficas divididas entre Direito Processual Civil, Direito do Consumidor e Sociologia. Ainda, se utilizará de exames quantitativos prévios já publicados, com análise estatística da matéria.

O primeiro tópico da pesquisa irá discutir os aspectos teóricos e jurídicos do incidente de resolução de demandas repetitivas para compreender qual o papel desempenhado por este instrumento processual na ordem jurídica. Em seguida, na segunda seção, será debatida a origem das demandas seriadas de consumo e seu tratamento jurídico. Por fim, na terceira e última etapa, o exame buscará estudos estatísticos para compreender como o incidente processual em discussão é empregado pelos tribunais brasileiros nas lides consumeristas.

\section{O INCIDENTE DE RESOLUÇÃO DE DEMANDAS REPETITIVAS E O CÓDIGO DE PROCESSO CIVIL}

Com a vigência do Código de Processo Civil de 2015, foi criado um novo panorama para a jurisprudência brasileira, denotando uma preocupação especial do legislador com questões ligadas 
ao caráter vinculante das decisões judiciais, mormente o intuito de criar uma sistemática de precedentes judiciais. Dentre os institutos desenhados pela dita legislação, destaca-se o incidente de resolução de demandas repetitivas, então objeto de estudo desta seção. Antes de discutir a entidade em si, cabe debater sobre o substrato teórico que alicerça as premissas encontradas na lei processual.

A perspectiva de manter a jurisprudência dos tribunais íntegra e coesa consiste em uma aplicação direta da teoria de Ronald Dworkin ao direito brasileiro, consoante serem empregados os termos característicos de sua obra, como é perceptível pela leitura do art. $926^{80}$ do Código de Processo Civil. (PEREIRA, 2018, p. 169 - 170). De acordo com os postulados escrutinados por Dworkin, o direito deve comportar-se como um romance em cadeia, enquanto um empreendimento literário comum entre vários juízes, no qual cada julgador deverá se reportar aos capítulos anteriores - decisões - para escrever o seu, mantendo o sistema jurídico coeso. Em outras palavras, a expectativa é que o juiz enfrente os precedentes anteriores, em sua decisão, para manter o mínimo de segurança jurídica e pertinência do julgado com a estrutura normativa-jurídica. (DWORKIN, 2008, p. $238-241)$.

Logo, cabe ao juiz, quando exercer a judicatura, manter a integridade do direito, sendo a própria releitura da tradição histórica dos precedentes uma ferramenta adicional na construção da resposta correta aplicável ao caso em espeque. Isto se deve ao fato de que o romance em cadeia assinala a validade da norma em relação ao sistema jurídico como um todo.

Ainda que a teoria de Dworkin seja cunhada para os casos difíceis - aqueles que não possuem resposta direta no ordenamento jurídico e que devem ser reconstruídas, pelo julgador, a partir do cotejamento entre os precedentes judiciais, os princípios e as políticas (PEREIRA, 2018, p. 135 - 136) -, fato é que esta visão jusfilosófica contaminou o legislador na feitura do Código, o que justifica esta breve digressão acerca do que representam os conceitos de integridade e coesão transcritos pelo já mencionado art. 926.

Neste esteio, o Código de Processo Civil consagra uma sistemática híbrida entre os modelos de common law e civil law, ao trazer a figura do precedente como dispositivo apto a resolver a franca litigiosidade que se faz presente nos ambientes forenses. Os precedentes são normas criadas

\footnotetext{
${ }^{80}$ Art. 926. Os tribunais devem uniformizar sua jurisprudência e mantê-la estável, íntegra e coerente. $\S 1^{\circ} \mathrm{Na}$ forma estabelecida e segundo os pressupostos fixados no regimento interno, os tribunais editarão enunciados de súmula correspondentes a sua jurisprudência dominante. $\S 2^{\circ}$ Ao editar enunciados de súmula, os tribunais devem ater-se às circunstâncias fáticas dos precedentes que motivaram sua criação.
} 
pelos tribunais com poder vinculante e que podem servir para resolução de casos idênticos, mitigando as possibilidades de interpretação e aplicação diferenciada. (KELSEN, 1999, p. 278 279)

Daí que desponta um ensaio pela padronização decisória nas demandas em série, materializado em diversas técnicas de julgamento, das quais o incidente de resolução de demandas repetitivas é um dos instrumentos eleitos para efetivar tal arquétipo. (NUNES, BAHIA, PEDRON, 2020, p. 660). É que um dos objetivos da legislação processual é fundar um microssistema de litigiosidade repetitiva, apto a solucionar aquelas demandas sobre direitos individuais homogêneos, as quais são objeto de ações propostas de forma seriada e têm como pano de fundo um mesmo contexto fático e jurídico. (NUNES, BAHIA, PEDRON, 2020, p. 676 - 679).

O incidente de resolução de demandas repetitivas, enquanto componente do sistema acima mencionado, tem sua inspiração na dogmática processual alemã, que dispõe de instituto semelhante, denominado de Musterverfahren ${ }^{81}$. No direito alemão, é delineado um procedimento padrão para os feitos que tratem de uma mesma situação jurídica, independentemente de as partes coincidirem, de modo que as questões comuns sejam analisadas pelo julgador e que forneçam um paradigma para os juízos originários. (KREBS, 2015, p. 176). Diferentemente da sistemática alemã, na qual o procedimento padrão tem natureza de incidente interlocutório, o Brasil estruturou o incidente de resolução de demandas repetitivas como ação autônoma. (NUNES, BAHIA, PEDRON, 2020, p. 730)

A disciplina do incidente de resolução de demandas repetitivas reside no art. $976^{82}$ do Código de Processo Civil. Para instalação do expediente processual, é necessário comprovar os dois requisitos: a existência de processos seriados de controvérsia comum e o risco de ofensa à segurança jurídica, dado que diferentes interpretações podem ser produzidas por juízes e pelos tribunais.

\footnotetext{
${ }^{81}$ Em tradução livre: procedimento-padrão.

82 Art. 976. É cabível a instauração do incidente de resolução de demandas repetitivas quando houver, simultaneamente: I - efetiva repetição de processos que contenham controvérsia sobre a mesma questão unicamente de direito; II - risco de ofensa à isonomia e à segurança jurídica. $\S 1^{\circ} \mathrm{A}$ desistência ou o abandono do processo não impede o exame de mérito do incidente. $\S 2^{\circ}$ Se não for o requerente, o Ministério Público intervirá obrigatoriamente no incidente e deverá assumir sua titularidade em caso de desistência ou de abandono. $§ 3^{\circ} \mathrm{A}$ inadmissão do incidente de resolução de demandas repetitivas por ausência de qualquer de seus pressupostos de admissibilidade não impede que, uma vez satisfeito o requisito, seja o incidente novamente suscitado. $§ 4^{\circ}$ É incabível o incidente de resolução de demandas repetitivas quando um dos tribunais superiores, no âmbito de sua respectiva competência, já tiver afetado recurso para definição de tese sobre questão de direito material ou processual repetitiva. $\S 5^{\circ}$ Não serão exigidas custas processuais no incidente de resolução de demandas repetitivas.
} 
A abrangência de processos compreende tanto aqueles de competência originárias dos tribunais quantos aqueles de primeira instância, desde que tenha havido algum julgamento que possibilite a subida da questão, pela via recursal, às instâncias superiores. (KREBS, 2015, p. 177). O requerimento de instalação será direcionado ao presidente da corte, podendo ser conhecido de ofício ou arguido por qualquer um dos interessados, seja parte, terceiro, Defensoria Pública ou Ministério Público, nos termos do art. 977.

É necessário que o interessado demonstre, efetivamente, que existe repetição entre as demandas e que o tribunal possui, em seu acervo, processo pendente de julgamento. (NUNES, BAHIA, PEDRON, 2020, p. 731). Com a admissão do incidente, serão suspensos os processos pendentes e que detenham pertinência com a temática em julgamento, consoante o art. $982^{83}$, inciso I, do Código de Processo Civil e o processo remetido a um órgão indicado pelo regimento interno de cada corte, consoante o art. $978^{84}$.

A etapa subsequente envolve a intimação do Ministério Público - quando este não for autor - e dos juízos de instância inferiores para que prestem as informações necessárias para subsidiar o processo cognitivo. Também é cabível a intervenção do amicus curiae no âmbito do incidente de resolução de demandas repetitivas, ampliando o alcance argumentativo da questão. Todos aqueles que serão afetados pelo julgamento poderão se manifestar no incidente, possibilitando que diversas perspectivas fáticas e jurídicas sejam visualizadas pelo tribunal. (PEREIRA, 2018, p. 115).

Com a resolução da questão, entra-se na última fase, na qual o precedente definido é aplicado nos processos pendentes, até posterior revisão, que pode ocorrer pela via da superação das razões decisórias ou por uma nova situação fática que fuja ao seu alcance. O mesmo órgão responsável por julgar o incidente também poderá avaliar as revisões. Dessas decisões caberá recurso especial ou extraordinário, a depender da natureza do mérito, presumindo-se a repercussão geral. (NUNES, BAHIA, PEDRON, 2020, p. 735 - 736).

Independentemente de qualquer crítica que possa ser feita sobre a cultura de precedentes no direito brasileiro, sobre o instituto e ainda diante da pendência de plena regulamentação, fato é que se tem um instrumento com possível potencial para apaziguar a litigiosidade de massas que se

\footnotetext{
${ }^{83}$ Art. 982. Admitido o incidente, o relator: I - suspenderá os processos pendentes, individuais ou coletivos, que tramitam no Estado ou na região, conforme o caso;

${ }^{84}$ Art. 978. O julgamento do incidente caberá ao órgão indicado pelo regimento interno dentre aqueles responsáveis pela uniformização de jurisprudência do tribunal.

Parágrafo único. O órgão colegiado incumbido de julgar o incidente e de fixar a tese jurídica julgará igualmente o recurso, a remessa necessária ou o processo de competência originária de onde se originou o incidente.
} 
faz presente em algumas áreas, a exemplo do direito do consumidor. Satisfeita a introdução do incidente de resolução de demandas repetitivas, faz-se necessário discutir as demandas seriadas em matéria consumerista, objeto da próxima seção.

\section{AS DEMANDAS REPETITIVAS EM MATÉRIA DE DIREITO DO CONSUMIDOR}

Com o passar do tempo, a sociedade brasileira vem presenciando um crescimento maciço nas relações de consumo, que se tornam cada vez mais variadas. Dentre essas relações, as compras via internet em lojas virtuais - seja por comodidade, economicidade, praticidade, acessibilidade e outros - vêm gerando os mais variados tipos de negociação entre consumidores e fornecedores, demonstrando o rompimento de barreiras territoriais para a perfectibilização dos negócios entre as partes da relação de consumo. (BAUMAN, 1998, p. 26)

Isto revela um aprimoramento tanto na característica dos indivíduos quanto ao seu perfil de consumo como na tipologia dos contratos realizados, afinal, os membros da sociedade são classificados de acordo com a sua condição e capacidade de serem consumidores, tendo em vista que estes sempre estão ávidos pelo desejo e pela satisfação de consumir em um curso espaço de tempo (BAUMAN, 1998, p. 82 - 83).

Outro ponto importante a ser exposto é a velocidade com a qual se materializam as relações de consumo no atual mundo globalizado, trazendo a classificação atual da sociedade como consumista em face da impaciência e da impetuosidade das pessoas em se interessar e se desinteressar pelos bens disponíveis, ultrapassando os limites da necessidade real e natural (BAUMAN, 1998, p. 83). Portanto, as ações humanas são configuradas tão somente no desejo momentâneo e constante de experimentar uma sensação de satisfação ainda não vivenciada, anseio esse fomentado pela indústria que a todo tempo inventa um novo objeto capaz de seduzir os insaciáveis consumidores.

$\mathrm{Na}$ mesma rapidez com a qual surge o interesse por uma mercadoria, surge o desinteresse e subsequente descarte imediato do bem, porquanto já substituído por outro novo. A materialização deste processo dar-se através da divulgação exagerada de publicidade, muitas vezes realizada de forma abusiva pelos fornecedores, com o objetivo de lucrar com a produção e o consumo em massa. Não obstante, ainda persiste o fornecimento de produtos impróprios para consumo, defeituosos e 
serviços de má qualidade, o que gera uma parcela considerável de consumidores insatisfeitos, cujos direitos eventualmente desrespeitados nestas relações serão solucionados pelo poder judiciário.

O aumento da litigiosidade se verifica em duas frentes: de um lado, as práticas desleais dos fornecedores; de outro, a ausência de uma via administrativa capaz de solucionar prejuízos causados aos consumidores. Neste diapasão, a falta de uma fiscalização por parte das agências reguladoras responsáveis também contribui para a sobrecarga do Poder Judiciário com as chamadas demandas de massa. (SAID FILHO, 2016, p. 95 - 96).

Prova disso é o relatório anual elaborado pelo Conselho Nacional de Justiça, chamado de "Justiça em Números", o qual aponta crescimento anual e paulatino no ajuizamento de demandas de massa envolvendo os chamados grandes litigantes ou litigantes habituais, malgrado o alto investimento anual dos tribunais brasileiros em estrutura, pessoal, aparato tecnológico, entre outros, com a finalidade de reduzir ou frear esses números e vislumbrar um dia um Judiciário numa perspectiva sustentável. (DIAS, 2017, p. 125).

As demandas de massa são as lides concernentes a direitos individuais homogêneos nas quais há controvérsia preponderantemente sobre as mesmas questões de direito e, portanto, responsáveis pela litigiosidade enfrentada pelos tribunais brasileiros. (DANTAS, 2014, p. 69). Já os grandes litigantes ou litigantes habituais são aqueles que detém aparato jurídico próprio para atuar em prol dos interesses de grandes empresas como bancos, planos de saúde, empresas de telefonia, grandes magazines, entre outros que encabeçam a lista dos maiores litigantes brasileiros. Para estas entidades, quanto mais tempo um processo tramita em sede de tribunais, mais tempo é ganho para efetuar a reparação devida ao consumidor lesado. (CNJ, 2011).

Nesse cenário, com a égide jurídica trazida pelo Código de Processo Civil, possibilita-se o julgamento de improcedência liminar do pedido quando reconhecido o entendimento firmado em incidente de resolução de demandas repetitivas ou assunção de competência, nos termos dos artigos $332^{85}$, inciso III, e $928^{86}$, inciso I.

Essa ferramenta veio como forma de se garantir um tratamento adequado das demandas de massa, porquanto a estrutura atual do judiciário e a sistemática processual são preparadas para

\footnotetext{
85 Art. 332. Nas causas que dispensem a fase instrutória, o juiz, independentemente da citação do réu, julgará liminarmente improcedente o pedido que contrariar: III - entendimento firmado em incidente de resolução de demandas repetitivas ou de assunção de competência.

${ }^{86}$ Art. 928. Para os fins deste Código, considera-se julgamento de casos repetitivos a decisão proferida em: I - incidente de resolução de demandas repetitivas.
} 
receber somente demandas individualizadas, conquanto as de massa exigem um tratamento diferenciado a fim de conter ou frear a litigiosidade seriada. (TEMER, 2018, p. 33)

O incidente de resolução de demandas repetitivas pode reduzir o tempo de duração do processo, tendo em que a aplicação de uma tese já fixada por uma instância superior limita a rediscussão do tema e garante previsibilidade e segurança jurídica (MARINONI, 2011, p. 109) às decisões proferidas em primeira instância, a qual é responsável pela maioria das ações de direito do consumidor, com base nos relatórios anuais do Conselho Nacional de Justiça.

Ademais, o incidente de resolução de demandas repetitivas configura-se como um meio fidedigno de participação para a contribuição de interessados no debate para a fixação da tese jurídica, uma vez que o relator deverá selecionar os processos mais representativos da controvérsia e, após a admissão do incidente, se preenchidos os requisitos, a ele deverá ser dada a devida publicidade como forma de legitimação da tese firmada (TEMER, 2018, p. 143).

A publicidade garante a participação da sociedade, das partes e de qualquer outro interessado, na forma do art. $983^{87}$ do Código de Processo Civil, pois as decisões proferidas no âmbito dos tribunais, em sede de demandas seriadas, geram repercussões a níveis social, financeiro e político. (MENDES, TEMER, 2015). Por esta razão, os argumentos bem apresentados possibilitam melhor apreciação da causa, tendo no debate o meio necessário para se conseguir a legitimidade da qual devem ser revestidas todas as decisões, daí que a participação, por intermédio de amicus curiae, daqueles alcançados pela norma, bem como a garantia de audiências públicas e da oitiva de partes desinteressadas no litígio, garante o aporte de informações necessárias à análise do objeto do incidente e à formação do precedente. (DIDIER JUNIOR, 2007, p.240)

Essa perspectiva dialógica promove a manifestação aberta de uma política pluralista baseada no consenso ou na elaboração de uma opinião autêntica concebida através da participação e da integração social entre indivíduos, o que materializa uma democracia procedimental ativa. (GÓES, 2013, p. 45 - 46)

Em um panorama no qual as relações de consumo são feitas das mais variadas formas, é preciso assegurar previsibilidade máxima para a garantia de uma ordem justa e racional

\footnotetext{
${ }^{87}$ Art. 983. O relator ouvirá as partes e os demais interessados, inclusive pessoas, órgãos e entidades com interesse na controvérsia, que, no prazo comum de 15 (quinze) dias, poderão requerer a juntada de documentos, bem como as diligências necessárias para a elucidação da questão de direito controvertida, e, em seguida, manifestar-se-á o Ministério Público, no mesmo prazo. $\S 1^{\circ}$ Para instruir o incidente, o relator poderá designar data para, em audiência pública, ouvir depoimentos de pessoas com experiência e conhecimento na matéria. $\S 2^{\circ}$ Concluídas as diligências, o relator solicitará dia para o julgamento do incidente.
} 
(MARIONI, 2016, p. 37), com a observância da unidade do direito; da promoção de igualdade entre o jurisdicionado; e até mesmo da racionalidade econômica da máquina judiciária, evitando a interposição desnecessária de recursos às instâncias superiores.

É neste prisma que o Código de Processo Civil debuta uma ordem jurídica instituída com base em decisões produzidas de acordo com o entendimento vinculante, seja ele simulado ou produzido em sede de incidente, como maneira de efetivar o princípio da segurança jurídica por intermédio da certeza, da estabilidade, da previsibilidade e da confiança. (CARVALHO, 2019, p. 250 - 251). Afinal, segurança jurídica e justiça estão intimamente ligadas, considerando que a primeira significa a imutabilidade de regramentos jurídicos ou interpretação dos tribunais, revestindo as decisões de um caráter absoluto. A segurança jurídica é importante e se justifica para a estabilização das relações sociais (NASCIMENTO, THEODORO JÚNIOR, FARIA, 2011.p. 107)

Nesse sentido, não se pode aceitar posicionamentos jurisprudenciais dissonantes para casos idênticos, pois tal prática confere insatisfação e perplexidade aos cidadãos afetados por decisões opostas acerca dos mesmos direitos na seara consumerista. (RODRIGUES, 2013, p. 30). Ações estas que são as responsáveis pelo abarrotamento das instâncias inferiores dos tribunais às quais pode ser dado tratamento igualitário e único com base no posicionamento colegiado das cortes.

A ampliação do acesso à justiça conferiu à sociedade contemporânea instrumentos para a garantia e a efetivação de seus direitos por meio das demandas individuais. Dados os prejuízos causados aos litigantes eventuais, os consumidores vêm ingressando anualmente com mais e mais processos, o que acarreta no comprometimento da duração razoável do processo, da segurança jurídica e da isonomia. É o crescimento exponencial, visto sob a roupagem de processos repetitivos, que acarreta o abarrotamento de todas as instâncias dos tribunais, principalmente as inferiores, o que demanda esforços e gastos cada vez maiores para diminuir o número de processos. Para solucionar este cenário, sob pena de colapso no funcionamento da estrutura judicial, é que o legislador lança mão do incidente de resolução de demandas repetitivas. Feita tal digressão, o estudo irá para a próxima etapa, com o fito de discutir a aplicação do incidente de demandas repetitivas nos processos seriados que tratam sobre direito do consumidor nos Tribunais de Justiça do Brasil. 


\section{A UTILIZAÇÃO DO INCIDENTE DE RESOLUÇÃO DE DEMANDAS REPETITIVAS NA SEARA CONSUMERISTA}

Tendo sido verificados, até então, os conceitos que estão por trás do incidente de resolução de demandas repetitivas, bem como discutidas as bases para os processos seriados dentro das demandas de consumo, cabe agora identificar a aplicação do instituto processual em exame nas demandas consumeristas.

A investigação será realizada a partir dos dados gerados pelo Observatório Brasileiro de $\mathrm{IRDRs}^{88}$, grupo de pesquisa vinculado à Faculdade de Direito de Ribeirão Preto e que realiza o acompanhamento dos incidentes de demanda repetitivas suscitados perante os tribunais brasileiros, analisando as questões vinculadas à aplicação, admissibilidade e julgamento de mérito. A investigação do grupo compreendeu os 27 (vinte e seis) Tribunais de Justiça estaduais e do Distrito Federal, além dos Tribunais Regionais Federais das 5 (cinco) regiões.

No período de 18 de março de 2016 a 15 de junho de 2018, foi realizado o exame de admissibilidade de 677 (seiscentos e setenta e sete) incidentes, dos quais 68 (sessenta e oito) tiveram o mérito julgado. (ZUFELATO, 2019b, p. 25 -26). Deste universo, 197 (cento e noventa e sete) foram admitidos, 1 (um) foi transformado em diligência, 6 (seis) foram extintos, 453 (quatro centos e cinquenta e três) não tiveram admissão, 7 (sete) não foram conhecidos, 12 (doze) tiveram o mérito prejudicado e 1 (um) foi suspenso. (ZUFELATO, 2019b, p. 28 - 29). No espectro do direito do consumerista, foram admitidos 11 (onze) incidentes de resolução de demandas repetitivas, (ZEFELATO, 2019b, p. 68), dos quais 5 (cinco) tiveram intervenção de terceiros no exame de mérito. (ZEFELATO, 2019b, p. 75).

Compulsando o formulário de coleta de dados de exame de mérito, disponível no acervo de dados $^{89}$ do Observatório Brasileiro de IRDRs, verifica-se que foram julgados 5 (cinco) incidentes em matéria consumerista. (ZUFELATO, 2019a). São os seguintes feitos:

a) Processo paradigma de número 0023203-35.2016.8.26.0000, julgado pela Turma Especial de Direito Privado do Tribunal de Justiça de São Paulo;

\footnotetext{
${ }^{88} \mathrm{O}$ sítio virtual do grupo pode ser acessado através do endereço: http://observatorioirdr.direitorp.usp.br/

${ }^{89} \mathrm{O}$ acesso pode ser feito através do seguinte endereço virtual: http://observatorioirdr.direitorp.usp.br/banco-de-dados$2 /$
} 
b) Processo paradigma de número 0240033-82.2016.8.21.7000, julgado pela Quinta Turma Cível do Terceiro Grupo Cível do Tribunal de Justiça do Rio Grande do Sul;

c) Processo paradigma de número 0032321-30.2016.8.19.0000, julgado pela Seção Cível Comum do Tribunal de Justiça do Rio de Janeiro;

d) Processo paradigma de número 0378378-98.2016.8.13.0000, julgado pela Segunda Seção Cível do Tribunal de Justiça de Minas Gerais;

e) Processo paradigma de número 039/2016, julgado pela Turma de Uniformização de Interpretação de Lei do Tribunal de Justiça do Espírito Santo.

Fora os processos mencionados nas alíneas "a" e "e", nos demais foram sobrestados os processos pendentes no respectivo tribunal que versassem sobre a mesma matéria. Afora o processo mencionado na alínea "e", cujos dados não puderam ser obtidos, nos outros feitos não foram requisitadas informações a órgãos diversos e não ocorreu modulação de efeitos. Afora o feito da aliena "a", nenhum dos demais levou a apresentação de Recurso Especial ao Superior Tribunal de Justiça. Os julgados mencionados nas alíneas "a" e "b" foram suscitados por pessoas física e jurídica de direito privado, enquanto o da aliena "c" foi levantado por pessoas física, jurídica de direito privado e privada de direito público. Por fim, o processo da alínea "d" foi levantado por pessoa jurídica de direito público. (ZUFELATO, 2019a).

O incidente de resolução de demandas repetitivas de número 0023203-35.2016.8.26.0000 apreciado pelo Tribunal de Justiça de São Paulo teve como objeto de discussão os requisitos e efeitos do atraso de entrega de unidades autônomas em construção aos consumidores. O julgado redundou nas seguintes teses sendo fixadas:

$\mathrm{Na}$ aquisição de unidades autônomas futuras, financiadas na forma associativa, o contrato deverá estabelecer de forma expressa, clara e inteligível o prazo certo para formação do grupo de adquirentes e para entrega do imóvel. [...] O atraso da prestação de entrega de imóvel objeto de compromisso de compra e venda gera obrigação da alienante indenizar o adquirente pela privação injusta do uso do bem [...]É ilícito o repasse dos "juros de obra", ou "juros de evolução de obra", ou taxa de evolução da obra", ou outros encargos equivalentes após o prazo ajustado no contrato para entrega das chaves da unidade autônoma, incluído período de tolerância. [...]A restituição de valores pagos em excesso pelo promissário comprador em contratos de compromisso de compra e venda far-se-á de modo simples, salvo má-fé do promitente vendedor. [...]descumprimento do prazo de entrega de imóvel objeto de compromisso de venda e compra, computado o período de tolerância, não faz cessar a incidência de correção monetária, mas tão somente dos juros e multa contratual sobre o saldo devedor. [...] Não se aplica a multa prevista no artigo 35, parágrafo $5^{\circ}$, da Lei n. 4.591/64 para os casos de atraso de entrega das unidades autônomas aos promissários compradores. (TJSP, 2017) 
Já o incidente de resolução de demandas repetitivas de número 0240033-82.2016.8.21.7000 do Tribunal de Justiça do Rio Grande do Sul abordou o conflito de competência para julgamento de ações indenizatórias por danos ajuizada contra estabelecimento enquadrado como fornecedor, eis que é facultado ao consumidor ajuizar a ação em seu próprio domicílio. A corte concluiu que, em "[t]ratando-se de conflito de competência entre os foros da capital, o litígio deve tramitar naquele escolhido pelo consumidor, desde que observada uma das opções legais, descabida a declinação de ofício.” (TJRS, 2018).

De seu turno, o incidente de resolução de demandas repetitivas de número 003232130.2016.8.19.0000 que foi objeto de análise no Tribunal de Justiça do Rio de Janeiro teve como pano de fundo a "legitimidade passiva nas ações onde se busca adequação dos descontos de empréstimos consignados à margem" e consagrou que a "a legitimidade passiva ordinária é das instituições financeiras que concederam crédito ao autor". Assim, "não há litisconsórcio necessário entre as instituições financeiras e a fonte pagadora." Caso seja "opção do consumidor, a fonte pagadora pode figurar no polo passivo, como litisconsorte facultativo, observada a imputação à mesma de conduta própria" (TJRJ, 2016).

Por sua vez, o incidente de resolução de demandas repetitivas de número 037837898.2016.8.13.0000 arguido perante o Tribunal de Justiça de Minas Gerais versou sobre "o cabimento de medida cautelar de exibição de documentos para obtenção de documentos a serem fornecidos pelos Órgãos de Proteção ao Crédito". Findou, como tese jurídica acatada, que é:

[...] cabível o habeas data para obtenção de informações constantes em banco de dados e cadastros restritivos de crédito de consumidores, desde que, conforme expressa previsão legal, exista prova da recusa ao acesso às informações ou do decurso de mais de dez dias sem decisão. [...] Inexiste interesse de agir da parte que ajuíza ação de exibição de documentos em desfavor dos órgãos de proteção ao crédito para obtenção de documentos referentes à negativação. (TJMG, 2016)

O último julgamento identificado é o do incidente de resolução de demandas repetitivas de número 039/2016 apreciado pelo Tribunal de Justiça do Espírito Santo. Ele buscou fornecer uma tese jurídica para as cobranças das tarifas de cadastro e de avaliação do bem, de seguro proteção financeira, da taxa de registro de gravame eletrônico e de serviços de terceiros nos contratos de financiamento de veículos. Os julgadores concluíram que:

Não há ilicitude na contratação e cobrança do "seguro de proteção financeira", devendo verificar-se, no caso concreto, se houve adesão livre do consumidor, constando dos autos, 
além de sua opção de contratação, a respectiva apólice. [...] Os custos decorrentes do registro de gravame eletrônico, medida inerente à atividade da instituição financeira, devem ser inteiramente por ela suportados, sendo ilícita a transferência de tais custos ao adquirente do veículo. (TJES, 2016)

Apesar de existirem poucos julgados de incidentes de demandas repetitivas de consumo, fato é que a própria arguição destes institutos perante os tribunais tem o condão de assegurar uma maior segurança jurídica e celeridade aos processos, eis que a tese fixada pela corte permitirá a aplicação imediata e vinculante aos demais órgãos judicantes daquela competência, até posterior superação ou modificação do precedente elaborado.

\section{CONSIDERAÇÕES FINAIS}

No Brasil, em face da morosidade que permeia os tribunais, o judiciário não socorre a contento os consumidores invectivados diariamente por grandes empresas e grandes grupos detentores de poderio econômico e jurídico, capazes de litigarem com tempo e condições em seu favor, locupletando-se indevidamente à custa do tempo e do investimento feito pelo consumidor. Assim, destaca-se o potencial que possui o incidente de resolução de demandas repetitivas para conferir celeridade aos processos em matéria de consumo.

Os conceitos de integridade e coesão propostos inicialmente pela teoria de Ronald Dworkin ganharam força e importância no Código de Processo Civil de forma a privilegiar a decisão fundada no precedente com força, fundamentação e poder vinculante como forma de aplicação imediata para casos idênticos.

O Incidente de resolução de demandas repetitivas é um instrumento de manejo capaz de diminuir ou frear a litigiosidade atual verificada principalmente nos tribunais de primeira instância em face do constante número de situações contratuais realizadas nas relações de consumo atual, estas cada vez mais elaboradas e dos mais diversos tipos e formas, as quais ensejam uma solução rápida quando frustradas as expectativas dos consumidores em face das práticas abusivas perpetradas diariamente em todo o Brasil.

Infelizmente, malgrado a divulgação maciça do Código de Defesa do Consumidor, a parte hipossuficiente da relação de consumo apenas dispõe do Poder Judiciário como a ultima ratio para a satisfação de um direito na lei garantida, o que faz do Judiciário o balcão de reclamações de 
consumidores insatisfeitos com produtos que não atendem às suas expectativas ou serviço aquém do esperado. Prova disso é o alto número de demandas ajuizadas diariamente, conforme os números demonstrados pelo Conselho Nacional de Justiça, os quais apontam para um colapso do sistema em pouco tempo.

Diante desse quadro, a necessidade de se objetivar um Poder Judiciário sustentável, tanto do ponto de vista material e humano, quanto do ponto de vista processual no sentido de garantir um posicionamento linear em seus julgados, faz com que sejam empregados esforços em um julgamento contínuo para conter o ajuizamento maciço de demandas.

Ou então tentar equalizar, minimamente, o número de ações novas com o de ações julgadas, sob pena do comprometimento dos princípios da segurança jurídica, bem como do princípio da inafastabilidade da jurisdição, porquanto o direito tardio não cumpre a sua finalidade.

Apesar das parcas decisões em matéria consumerista arguidas em sede de Incidente, não se pode negar a relevância do instituto na verticalização dos julgamentos dessa matéria, pois estes podem garantir celeridade no julgamento, poupando os entraves muitas vezes colocados pelos grandes litigantes, os quais acabam por fulminar o direito do consumidor prejudicado.

Assim, o Incidente de Resolução de Demandas Repetitivas na seara consumerista se afigura razoável ferramenta para julgamentos maciços em face da similaridade de matérias chegadas diariamente nos tribunais brasileiros, sem contar na fundamentação pautada na argumentação, o que garante legitimidade na decisão, com privilégio do Princípio da segurança jurídica, o qual norteou fortemente a nova égide do Código de Processo Civil, bem como o ordenamento jurídico como um todo.

\section{REFERÊNCIAS}

BAUMAN, Zygmunt. Globalização: as consequências humanas. Rio de Janeiro: Jorge Zahar, 1998.

BRASIL. Conselho Nacional de Justiça. (Org.). 100 maiores litigantes. Brasília: CNJ, 2011. Disponível em: http://www.cnj.jus.br/images/pesquisasjudiciarias/pesquisa_100_maioress_litigantes.pdf. Acesso em: 16 mar. 2020.

BRASIL. Tribunal de Justiça de Minas Gerais. IRDR nº 0032321-30.2016.8.19.000. Relatora: Desembargadora Juliana Campos Horta. Belo Horizonte, MG, 26 de setembro de 2016. Diário de Justiça do Estado de Minas Gerais. Belo Horizonte, 30 set. 2016. 
BRASIL. Tribunal de Justiça do Espírito Santo. IRDR n 39/2016. Relator: Juiz de Direito Lailton dos Santos. Vitória, ES, 25 de novembro de 2016. Diário de Justiça do Espírito Santo. Vitória, 05 dez. 2016.

BRASIL. Tribunal de Justiça do Rio de Janeiro. IRDR no 0032321-30.2016.8.19.000. Relatora: Desembargadora Natacha Nascimento Gomes Tostes Gonçalves de Oliveira. Rio de Janeiro, RJ, 30 de maio de 2017. Diário de Justiça do Rio de Janeiro. Rio de Janeiro, 22 jul. 2017.

BRASIL. Tribunal de Justiça do Rio Grande do Sul. IRDR nº 0023203-35.2016.8.26.0000. Relator: Desembargador Francisco Eduardo Loureiro. São Paulo, SP, 31 de agosto de 2017. Diário de Justiça do Estado de São Paulo. São Paulo, 15 set. 2017.

BRASIL. Tribunal de Justiça de São Paulo. IRDR nº 0240033-82.2016.8.21.7000. Relator: Desembargador Bayard Ney de Freitas Barcellos. Porto Alegre, RS, 19 de março de 2018. Diário de Justiça. Porto Alegre, 10 abr. 2018.

CARVALHO. Osvaldo Ferreira de. Segurança jurídica e a eficácia dos direitos sociais fundamentais. Curitiba: Juruá, 2017

DANTAS, Buno. Teoria dos recursos repetitivos: tutela pluri-individual nos recursos dirigidos ao STF e ao STJ. São Paulo: Revista dos Tribunais, 2014.

DIAS. Bruno de Macedo. A constitucionalidade de filtros ao acesso à justiça como mecanismos para assegurar o funcionamento sustentável do poder judiciário. Rio de Janeiro: Lumen Juris, 2017.

DIDIER JUNIOR, Fredie. et al. Julgamento de casos repetitivos. Salvador: Juspodivm, 2007.

DWORKIN, Ronald. Uma questão de princípio. Trad. de Luís Carlos Borges. São Paulo: Martins Fontes, 2001.

GÓES, Ricardo Tinoco de. Democracia deliberativa e jurisdição: a legitimidade da decisão judicial a partir e para além da teoria de J. Habermas. Curitiba: Juruá, 2013.

KELSEN, Hans. Teoria pura do direito. Trad. de João Baptista Machado. 6. ed. São Paulo: Martins Fontes, 1999.

KLAUSNER, Eduardo Antônio. Direito internacional do consumidor: a proteção no livre comércio internacional. Curitiba: Juruá, 2012.

KREBS, Hélio Ricardo Diniz. Sistemas de precedentes e direitos fundamentais. São Paulo: Revista dos Tribunais, 2015.

MARINONI. Luiz Guilherme. A ética dos precedentes: justificativa do novo CPC. São Paulo: Revista dos Tribunais, 2016. 
MARINONI, Luiz Guilherme. Precedentes obrigatórios. São Paulo: Revista dos Tribunais, 2011.

MENDES, Aluísio Gonçalves de Castro. TEMER; Sofia. O incidente de resolução de demandas repetitivas do novo Código de Processo Civil. Revista de Processo, vol. 243, maio/2015.

NASCIMENTO, Carlos Valder do. THEODORO JÚNIOR, Humberto. FARIA, Juliana Cordeiro de. Coisa julgada inconstitucional a questão da segurança jurídica. Belo Horizonte: Fórum, 2011.

NUNES, Dierle José Coelho. BAHIA, Alexandre Gustavo Melo Franco. PEDRON, Flávio Quinaud. Teoria geral do processo: com comentários sobre a virada tecnológica no direito processual. Salvador: JusPodivm, 2020.

PEREIRA, Carlos André Maciel Pinheiro. Jurisdição procedimental: o agir comunicativo da opinião pública através do amicus curiae. Curitiba: Juruá, 2018.

RODRIGUES, Roberto de Aragão Ribeiro. Ações repetitivas: o novo perfil da tutela dos direitos individuais homogêneos. Curitiba: Juruá, 2013.

SAID FILHO, Fernando Fortes. (Re)pensando o acesso à justiça: a arbitragem como mecanismo alternativo à crise funcional do poder judiciário. Rio de Janeiro: Lumen Juris, 2016.

TEMER, Sofia. Incidente de resolução de demandas repetitivas. Salvador: Juspodivm, 2018.

ZUFELATO, Camilo (Org.). Formulário de coleta de dados: exame de mérito (até 15-06). Ribeirão Preto: Universidade de São Paulo, 2019. 27. Disponível em:

http://observatorioirdr.direitorp.usp.br/wpcontent/uploads/sites/400/2019/03/Formul\%C3\%A1rio-de-coleta-de-dados-Exame-dem\%C3\%A9rito-at\%C3\%A9-15-06.xlsx. Acesso em: 30 mar. 2020.

ZUFELATO, Camilo. (Org.). I relatório de pesquisa do observatório brasileiros de IRDRs: dados de incidentes suscitados de 18 de março de 2016 a 15 de junho de 2018. Ribeirão Preto: Universidade de São Paulo, 2019. Disponível em: http://observatorioirdr.direitorp.usp.br/wpcontent/uploads/sites/400/2019/12/I_Relat\%C3\%B3rio_Observat\%C3\%B3rio_IRDR_USP_Ribei r\%C3\%A3o-Preto.pdf. Acesso em: 30 mar. 2020.

THE REPEATING DEMAND RESOLUTION INCIDENT APPLIED TO CONSUMER LAW

\section{ABSTRACT}

The following article discusses the role given to the institute for solving repetitive demands within the procedural systematic and its application in 
the judicial processes based on consumer law. It employs the deductive method to conduct exploratory and qualitative research. It understands that the incident for resolution of repetitive demands is a tool created by the legislator to protect the legal security and relieve the courts in order to guarantee the procedural speed. It considers that the consumer demands is a result of post-modernity, because the consumer relations are part of the individual's own identity, so that the unresolved problems between consumers and suppliers end up docking at the judiciary power. It visualizes the incident for solving repetitive demands application in the consumer relations by the Brazilian's courts, based on statistical studies. Finally, it concludes that the incident for solving repetitive demands, despite its timid use, implies a tool that can be used to systematize the access to justice as an order of values to be delivered for the consumer.

Keywords: Institute for solving repetitive demands. Consumer relationship. Access to justice in the consumer law. 